\title{
External validation of a simple scoring system to predict pregnancy viability in women presenting to an early pregnancy assessment clinic
}

\author{
Osanna YK Wan *, Symphorosa SC Chan, Jacqueline PW Chung, Janice WK Kwok, Terence TH Lao, \\ DS Sahota
}

This article was published on $2 \mathrm{Apr}$

\section{A B S T R A C T}

Introduction: A scoring system combining clinical history and simple ultrasound parameters was developed to predict early pregnancy viability beyond the first trimester. The scoring system has not yet been externally validated. This study aimed to externally validate this scoring system to predict ongoing pregnancy viability beyond the first trimester.

Methods: This prospective observational cohort study enrolled women with singleton intrauterine pregnancies before 12 weeks of gestation. Women underwent examination and ultrasound scan to assess gestational sac size, yolk sac size, and fetal pulsation status. A pregnancy-specific viability score was derived in accordance with the Bottomley score. Pregnancy outcomes at 13 to 16 weeks were documented. Receiver-operating characteristic curve analysis was used to assess the discriminatory performance of the scoring system.

Results: In total, 1508 women were enrolled; 1271 were eligible for analysis. After adjustment for covariates, miscarriage (13\%) was significantly associated with age $\geq 35$ years (odds ratio $[\mathrm{OR}]=1.99$, 95\% confidence interval [CI]: 1.19-3.34), higher bleeding score $(\mathrm{OR}=2.34, \quad 95 \%$ CI: 1.25-4.38), gestational age ( $\mathrm{OR}=1.17,95 \% \mathrm{CI}: 1.13-1.22)$, absence of yolk sac (OR=4.73, 95\% CI: 2.11-10.62), absence of fetal heart pulsation $(\mathrm{OR}=3.57,95 \%$ CI: 1.87 6.84), mean yolk sac size (OR $=1.25$, $95 \%$ CI: 1.06 1.47), and fetal size (OR=0.82, 95\% CI: 0.77-0.88). The area under the receiver operating characteristic curve was 0.91 (95\% CI: 0.89-0.93). Viability score of $\geq 1$ corresponded to a $>90 \%$ probability of viable pregnancy.

Conclusions: The scoring system was easy to use. A score of $\geq 1$ could be used to counsel women who have a high likelihood of viable pregnancy beyond the first trimester.

\section{Hong Kong Med J 2020;26:102-10 \\ https://doi.org/10.12809/hkmj198276}

OYK Wan *, FHKAM (Obstetrics and Gynaecology), FHKCOG

SSC Chan, MD, FRCOG

JPW Chung, FHKAM (Obstetrics and Gynaecology), FHKCOG

JWK Kwok, BSc

TTH Lao, MD, FRCOG

DS Sahota, BEng, PhD

Department of Obstetrics and Gynaecology, The Chinese University of Hong Kong, Shatin, Hong Kong

* Corresponding author: osannawan@cuhk.edu.hk

\section{New knowledge added by this study}

- External validation of the Bottomley score was achieved and a cut-off viability score was established. Women with a viability score of $\geq 1$ had a $>90 \%$ probability that their pregnancy would be carried to beyond the first trimester.

- Miscarriage was significantly associated with age $\geq 35$ years, higher bleeding score, gestational age, absence of yolk sac, absence of fetal heart pulsation, mean yolk sac size, and fetal size.

- A pregnancy with a large subchorionic haematoma (ratio of mean subchorionic haematoma diameter to gestational sac diameter $>0.5$ ) was almost two-fold more likely to miscarry, compared with other pregnancies.

Implications for clinical practice or policy

- This scoring system allows gynaecologists to use simple clinical history and standard ultrasound measurements to predict pregnancy viability beyond the first trimester.

- This score could potentially enhance treatment of women who present with early pregnancy complications, including reassurance of viability among those with high scores and psychological preparation for miscarriage among those with low scores.

\section{Introduction}

Miscarriage is the most common early pregnancy complication, which constitutes a large burden for patients and the overall healthcare system. Approximately one in four women experiences early pregnancy loss during her lifetime; such losses have significant negative psychological and social impacts on affected women. ${ }^{1-4}$ Miscarriage has been ranked the second most common diagnosis for admissions in the past 10 years in Hong Kong. ${ }^{5}$ 
In-patient hospital admissions for miscarriage were considerably reduced following establishment of outpatient early pregnancy assessment clinics (EPACs) in various hospitals. Women visit EPACs to seek reassurance that their pregnancy remains viable, which may be difficult because gestational sac size and embryonic growth are not uniform ${ }^{6}$; moreover, estimates of gestational age are misleading in women with irregular menstrual periods. ${ }^{7,8} \mathrm{~A}$ score that signifies the likelihood of a viable pregnancy may be helpful for clinicians working in EPACs.,10 This score would enable clinicians to target appropriate early psychological or clinical support, thereby minimising psychological morbidity, especially for patients with finite resources.

Probability models to predict pregnancy viability have been reported; these combine clinical history, sonographic assessment of gestational sac and heart pulsation, and biochemical measurements. ${ }^{3,9,11-13}$ However, some models cannot be utilised in initial counselling, because they require calculators or biochemical measurements which may not yet be available. ${ }^{9,12,13}$ In a recent systematic review regarding prediction of miscarriage in women with viable intrauterine pregnancy, it was found that many combinations of markers have been tested with varying diagnostic accuracy; however, no meta-analysis could be performed on combination models. ${ }^{14}$ Furthermore, the meta-analysis did not involve assessment of the proportions of women with intrauterine pregnancy of uncertain viability, and no scoring system or cut-off value could be derived for counselling.

The Bottomley score ${ }^{11}$ is a scoring system independent of biochemical measurements, which utilises clinical and ultrasound parameters, including maternal age, severity of bleeding, and ultrasound features (eg, mean sizes of gestational sac and yolk sac, as well as presence of fetal heart pulsation). It has been validated in comparison with more complicated probability-based models in women with intrauterine pregnancy of uncertain viability; however, the validation study was limited by small sample size and the exclusion of one third of the eligible women due to missing variables and absence of data regarding pregnancy outcomes. ${ }^{12}$ The scoring system was also limited by the absence of data regarding body mass index (BMI) and smoking status, which might affect the likelihood of viable pregnancy. ${ }^{11}$ Furthermore, ethnicity influences miscarriage risk-black women are reportedly more likely to miscarry than white women, ${ }^{15}$ whereas rates among South and East Asian women are reportedly similar to those of white women after adjustment for confounders. ${ }^{16}$ The objective of the present study was to assess and validate the Bottomley score for prediction pregnancy viability until 16 weeks of gestation in a cohort of Chinese pregnant women

\section{妊娠初期評估診所求診婦女的胎兒存活預測： 簡易評分系統外部驗證 \\ 温綺琪、陳丞智、鍾佩樺、郭蘊琪、勞子僖、邵浩達}

引言：結合臨床病史和簡單超聲參數的評分系統用作預測早期妊娠胎 兒存活概率。評分系統尚未通過外部驗證。本研究旨在從外部驗證該 評分系統, 以預測早孕期後的持續娃娠能力。

方法：這項前瞻觀察隊列研究納入妊娠 12 週前單胎子宮內妊娠的婦 女。婦女接受檢查和超聲掃描以評估胎囊大小、卵黃囊大小和胎兒搏 動狀態。根據Bottomley評分得出特定於妊娠的胎兒存活評分。記錄 13至16週的妊娠結局。ROC曲線分析用於評估評分系統的區分性能。

結果：納入1508名女性, 其中 1271 名符合分析條件。協變量校正 後, 流產（佔總體 $13 \%$ ) 與以下情況呈顯著相關, 包括年齡 $\geq 35$ 歲 （比值比 $1.99 ， 95 \%$ 置信區間 1.19-3.34）、較高出血評分（比值比 $2.34,95 \%$ 置信區間 1.25-4.38 ）、胎齡（比值比 $1.17,95 \%$ 置信區間 1.13-1.22）、無卵黃囊（比值比 $4.73 ， 95 \%$ 置信區間2.11-10.62） 無胎兒心臟搏動（比值比3.57，95\%置信區間1.87-6.84）、卵黃囊平 均大小（比值比 $1.25 ， 95 \%$ 置信區間 1.06-1.47）和胎兒大小（比值比 0.82，95\%置信區間0.77-0.88）。曲線下面積為0.91（95\%置信區間 0.89-0.93）。存活力得分 $\geq 1$ 對應超過 $90 \%$ 的可行懷孕概率。

結論：研究顯示評分系統易於使用。存活力得分 $\geq 1$ 可用於為那些妊娠 三個月後有較高胎兒存活率的婦女提供諮詢。

who presented to our hospital with threatened miscarriage or abdominal pain before 12 weeks of gestation.

\section{Methods}

\section{Study design}

This non-interventional prospective observational study was performed at the Prince of Wales Hospital, Hong Kong, between July 2013 and June 2015. An out-patient EPAC is available in this hospital to receive referrals of first trimester pregnant women with vaginal bleeding, abdominal pain, or both, and suspected threatened miscarriage, threatened miscarriage with uncertain viability, and/or abdominal pain complicating intrauterine pregnancy; referrals were made by general practitioners or accident and emergency medical officers. All gynaecologists at the EPAC had $\geq 3$ years of experience in ultrasound scans, as well as in diagnosis and treatment of miscarriage.

\section{Patients and clinical assessment}

For this study, Chinese women aged $\geq 18$ years with a singleton intrauterine pregnancy, referred before 12 weeks of gestation based on last menstrual period, were invited to participate. Participants provided demographic data for both standard clinical treatment and determination of the pregnancy viability score. 
Women were excluded if they underwent pregnancy termination, had an ectopic or multiple pregnancy, had pregnancy at an unknown location, or were diagnosed with miscarriage at the time of initial presentation. Women with intrauterine pregnancy of uncertain viability underwent a second ultrasound examination after 7 to 14 days to determine fetal viability, in accordance with published guidelines. ${ }^{17-19}$

Detailed information regarding obstetrics history and history of the current pregnancy were obtained, including abdominal pain (graded by pain score) and vaginal bleeding (assessed using a pictorial blood loss chart with number of pads used; no bleeding was regarded as a score of 0 , while clots or flooding was regarded as a score of 4). Information regarding smoking status (smoker or non-smoker), alcohol intake, and BMI were collected. Smokers included women who continued to smoke, as well as those who had discontinued smoking $\leq 2$ weeks before presentation to our hospital.20 Alcohol users included women who consumed $>2$ units per day, once or twice per week, in the month before and during their pregnancy. ${ }^{21}$ Body mass index was classified in accordance with international classification as underweight, normal, overweight, or obese. ${ }^{22}$

\section{Ultrasound assessment}

All women underwent a structured ultrasound assessment. All transvaginal ultrasound scans were performed using a GE Voluson 730 ultrasound machine (GE Healthcare, Zipf, Austria) to ascertain the location and viability of the pregnancy. Mean gestational sac diameter, mean yolk sac diameter, size of fetal pole, and presence of fetal heart pulsation were documented. The Royal College of Obstetricians and Gynaecologists guidelines ${ }^{17,18}$ and National Institute for Health and Care Excellence guidelines ${ }^{19}$ were used for diagnosis of miscarriage, intrauterine pregnancy of uncertain viability, viable pregnancy, ectopic pregnancy, or pregnancy of unknown location. In women with a history of vaginal bleeding, a hypoechoic or anechoic crescentshaped area on ultrasound images was regarded as a subchorionic haematoma; its three-dimensional size was classified as small, medium, or large when its size ratio (relative to gestational sac size) was $<0.2$, $0.2-0.5$, or $>0.5$, respectively.

\section{Clinical score and patient treatment}

Each pregnancy was assigned a Bottomley score based on clinical history and ultrasound parameters. ${ }^{11}$ All clinicians were blinded to the score and all women in this study were treated in accordance with our established standard clinical protocols. Pregnancies were categorised as viable or miscarriage at the repeat ultrasound scan conducted between 13 and 16 weeks of gestation, according to the presence or absence of fetal heart pulsation. Women with miscarriage were treated in accordance with current guidelines. ${ }^{17,19}$ Watchful waiting, or medical or surgical evacuation of the uterus, were offered according to each patient's clinical condition. For medical evacuation, misoprostol $800 \mu \mathrm{g}$ vaginally was used as first-line treatment, with follow-up assessment to check for complete evacuation. Patient treatment was not affected by participation in the study.

\section{Ethics approval}

Ethics approval was obtained from the Joint Chinese University of Hong Kong-New Territories East Cluster Clinical Research Ethics Committee (Ref CREC-2013.348). Written informed consent was obtained from all participants.

\section{Sample size calculations}

Bottomley and colleagues ${ }^{11}$ reported that the areas under the receiver operating characteristic (ROC) curves of their score were 0.90 and 0.72 using a combination of history and ultrasound parameters and history alone, respectively. To determine whether the Bottomley score in our local population exceeded the discriminatory power of the historyalone model and achieved discriminatory power similar to that of the combined model, sample size analysis, using MedCalc Statistical Software version 18.5 (MedCalc Software bv, Ostend, Belgium), showed that a minimum sample size of 750 was required for a type 1 error of $1 \%$ and power of $90 \%$, with the assumption that miscarriage occurred in one of every 10 pregnancies. The planned sample size was increased to 1500 to allow for the worstcase scenario of $50 \%$ non-participation rate and $50 \%$ loss to follow-up rate.

\section{Statistical analysis}

Women were divided intoviable or miscarriage groups according to pregnancy outcome. Comparisons of socio-demographic and pregnancy characteristics between the two outcome groups were performed using the Chi squared test or Fisher's exact test, where appropriate, for categorical variables; the Mann-Whitney $U$ test with post hoc Bonferroni correction was used for comparisons of continuous variables. Adjusted odds ratios (ORs) and 95\% confidence intervals (CIs) of significant predictors of miscarriage were determined by multivariate logistic regression analysis. Receiver operating characteristic curves were constructed to determine the discriminatory performance of the Bottomley score, as well as to determine the Bottomley score which predicted $90 \%$ viable pregnancies at the repeat ultrasound scan. Probit regression, with Bottomley score as the only independent predictor, 
was performed to estimate the probability of an ongoing viable pregnancy beyond the first trimester. Bottomley scores were truncated to a minimum value of -12 and a maximum value of 18 , prior to Probit regression and ROC analyses. Patients lost to followup were excluded from the study. All analyses were performed using SPSS Statistics, version 20.0 (IBM Corp., Armonk [NY], United States) and MedCalc. $\mathrm{P}<0.05$ was considered statistically significant.

\section{Results}

\section{Patient characteristics and ultrasound measurements}

Of the 1508 women invited to participate, 54 (3.6\%) declined and two $(0.1 \%)$ were lost to follow-up at 13 to 16 weeks of gestation (Fig 1). Table 1 summarises the socio-demographic characteristics, clinical signs and symptoms, and ultrasound measurements in the two outcome groups. The Bottomley score ranged from -41 to $24 ; 36$ women $(2.8 \%)$ had a score of $\leq-12$, and $64(5.0 \%)$ had a score $\geq 18$, while the score ranged from -12 to +1 in women with a pregnancy of uncertain viability at first assessment.

\section{Risk of miscarriage}

Unadjusted and adjusted ORs for risk of miscarriage after adjusting for covariates are summarised in Table 2. Subchorionic haematoma was noted in 167 pregnancies (13.1\%), including 138 (82.6\%) with bleeding. Haematoma size relative to gestational sac size was significantly associated with miscarriage $\left(\chi^{2}=70.5, \mathrm{P}<0.05\right) \quad$ [Tables 1 and 2]. A pregnancy with a large haematoma was nearly two-fold more likely to miscarry, compared with other pregnancies (17/160 [10.6\%] vs 66/1111 [5.9\%]).

\section{Predictive performance of Bottomley score}

The area under the ROC curve of the discriminatory performance of the Bottomley score in all women was 0.91 (95\% CI: 0.89-0.93, $\mathrm{P}<0.001$ ). A score of $\geq 1$ had a sensitivity of $91 \%$ (95\% CI: 85.8-95.1\%) and a false positive rate of $26.7 \%$ (95\% CI: $24.1-29.4 \%$ ). Figure 2 and Table 3 show the observed and estimated viability of a pregnancy after the first trimester, compared with the viability estimates by Bottomley et $\mathrm{al}^{11}$ at each viability score. The estimated probability of viability for a particular pregnancy, based on the Bottomley score, was determined: $\operatorname{Probit}(\mathrm{p})=1.15109+0.17188 \times$ score .

The estimated probability of viability reported by Bottomley and colleagues ${ }^{11}$ was within the $95 \%$ CI of the estimated probability determined by our Probit(p) function if the viability score was $\geq 0$. The area under the ROC curve of the Bottomley score in women with a pregnancy of uncertain viability at initial presentation was only 0.74 (95\% CI: 0.67-0.80).

\section{Discussion}

To the best of our knowledge, this is the first report of independent external validation of the scoring system proposed by Bottomley et al. ${ }^{11}$ to predict early second trimester pregnancy viability in women with intrauterine pregnancy before 12 weeks of gestation. Moreover, it is the first study in a homogenous Chinese population. Our findings indicated that the Bottomley score could be used to predict the likely outcome of pregnancy, thus potentially alleviating maternal anxiety; this is particularly useful for women with symptoms of threatened miscarriage. The scoring system is simple to use and does not require a calculator (in contrast to previous models) ${ }^{8,11}$; moreover, it relies solely on information that can be readily obtained by any gynaecologist, without the need for blood tests.,12 Women with a Bottomley score of $\geq 1$ had a $>90 \%$ probability of pregnancy viability beyond the first trimester. These women could be reassured, and further ultrasounds could be avoided. A low Bottomley score was associated with increased likelihood of miscarriage, such that half of the women with a score of -7 or -6 were expected to miscarry; this proportion reached

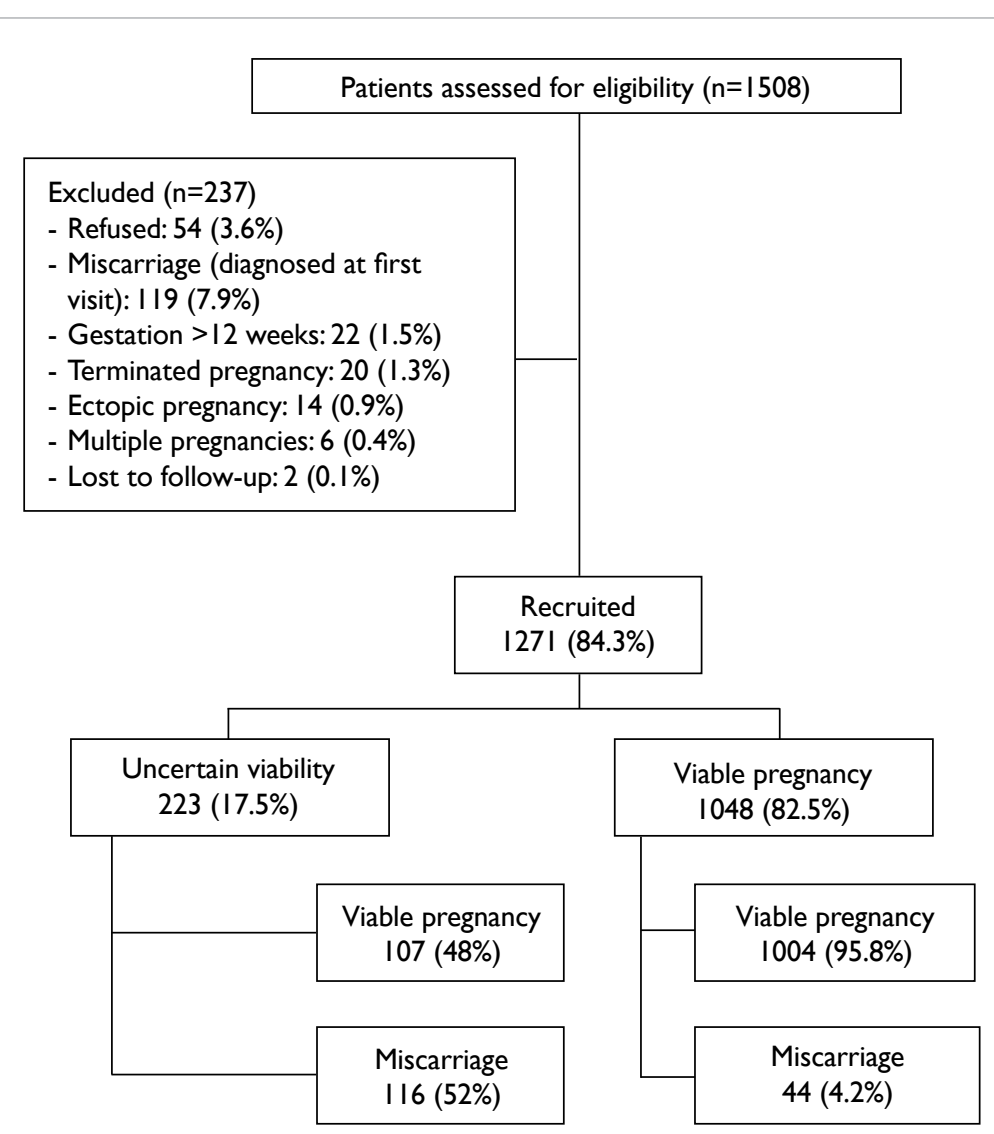

FIG I. Flowchart of study recruitment and eventual pregnancy outcome after first trimester 
TABLE I. Clinical and ultrasound characteristics of women with viable pregnancy or miscarriage after the first trimester

\begin{tabular}{|c|c|c|c|}
\hline Characteristics & Viable $(n=1111)$ & Miscarriage $(n=160)$ & $P$ value \\
\hline Age (years) & $31.0(18-44)$ & $33.0(20-47)$ & $<0.0001 \dagger$ \\
\hline$<35$ years & $891(80.2 \%)$ & $103(64.4 \%)$ & $<0.0001 \dagger$ \\
\hline$\geq 35$ years & $220(19.8 \%)$ & $57(35.6 \%)$ & \\
\hline Body mass index (kg/m2) & $21.2(14.0-41.3)$ & $21.5(16.5-35.0)$ & 0.33 \\
\hline Smoker (current or within past 2 weeks) & $150(13.5 \%)$ & $27(16.9 \%)$ & 0.25 \\
\hline Alcohol use (>2 units per day) & $28(2.5 \%)$ & $3(1.9 \%)$ & 0.65 \\
\hline Gravidity & $2(1-12)$ & $2(1-12)$ & 0.10 \\
\hline Nulliparous & $659(59.3 \%)$ & $91(56.9 \%)$ & 0.56 \\
\hline Previous first trimester miscarriage & $188(16.9 \%)$ & $31(19.4 \%)$ & 0.44 \\
\hline Abdominal pain & & & $0.012 \dagger$ \\
\hline No pain (score 0) & $347(31.2 \%)$ & $58(36.3 \%)$ & \\
\hline Mild pain (score 1-3) & $661(59.5 \%)$ & $77(48.1 \%)$ & \\
\hline Moderate/severe pain (score $>3$ ) & $103(9.3 \%)$ & $25(15.6 \%)$ & \\
\hline Bleeding score & & & $0.006 \dagger$ \\
\hline 0 & $239(21.5 \%)$ & $30(18.8 \%)$ & \\
\hline 1 & $739(66.5 \%)$ & $95(59.4 \%)$ & \\
\hline 2 & $128(11.5 \%)$ & $32(20.0 \%)$ & \\
\hline 3 & $5(0.5 \%)$ & $3(1.9 \%)$ & \\
\hline Gestational age (days) & $56(31-90)$ & $52(31-87)$ & $<0.0001 \dagger$ \\
\hline Gestational sac present & $1107(99.6 \%)$ & $146(91.3 \%)$ & $<0.0001 \dagger$ \\
\hline Mean gestational sac size (mm) & $28.9(2.5-71.6)$ & $16.8(2.5-43.5)$ & $<0.01 \dagger$ \\
\hline Yolk sac present & $1004(90.4 \%)$ & 99 (61.9\%) & $<0.0001 \dagger$ \\
\hline Mean yolk sac diameter (mm) & $3.4(1-21)$ & $3.3(1.2-8.5)$ & 0.74 \\
\hline Fetal heart pulsation & $1004(90.4 \%)$ & $44(27.5 \%)$ & $<0.0001 \dagger$ \\
\hline Fetal pole & $1035(93.2 \%)$ & $91(56.9 \%)$ & $<0.0001 \dagger$ \\
\hline Fetal size $(\mathrm{mm})$ & $14.9(0.7-72.4)$ & $4.7(1.4-32.1)$ & $<0.0001 \dagger$ \\
\hline Subchorionic haematoma & & & $0.041 \dagger$ \\
\hline None & $966(86.9 \%)$ & $138(86.3 \%)$ & \\
\hline Small (ratio $\neq<0.2)$ & $13(1.2 \%)$ & 0 & \\
\hline Medium $(0.2-0.5)$ & $66(5.9 \%)$ & $5(3.1 \%)$ & \\
\hline Large $(>0.5)$ & $66(5.9 \%)$ & $17(10.6 \%)$ & \\
\hline Bottomley pregnancy viability score§ & $5(-17-24)$ & $-6(-41-13)$ & $<0.0001 \dagger$ \\
\hline
\end{tabular}

* Data are shown as No. (\%) or median (range), unless otherwise specified

+ Statistically significant

‡ Ratio of subchorionic haematoma to gestational sac size

$\S$ Based on Table 6 in Bottomley et al"

$80 \%$ if the score was $\leq-12$. Proper counselling could be offered to prepare these women psychologically, thereby reducing the impact of pregnancy loss.

This scoring system incorporates several different variables that interact with each other. For example, a larger but empty gestational sac increases the likelihood of miscarriage, thus resulting in a lower (ie, more negative) score; however, this lower score would be counterbalanced by the presence of fetal heart pulsation and an appropriately sized yolk sac. In addition, although a negative score was unexpectedly determined for pregnancies with the presence of fetal heart pulsation, this negative score could be counterbalanced by a positive score for a larger gestational sac size.

Notable strengths in this study include its use of a priori determination of sample size to assess discriminatory performance. Moreover, the participation rate was high and few pregnancies were lost to follow-up. The resulting large sample size 
TABLE 2. Results of univariate and multivariate analysis of significant maternal and ultrasound characteristics for prediction of miscarriage after the first trimester in women presenting for early pregnancy assessment

\begin{tabular}{|c|c|c|c|c|c|c|}
\hline \multirow[t]{2}{*}{ Characteristic } & \multicolumn{3}{|c|}{ Univariate analysis } & \multicolumn{3}{|c|}{ Multivariate analysis* } \\
\hline & OR & $95 \% \mathrm{Cl}$ & $P$ value & aOR & $95 \% \mathrm{Cl}$ & $P$ value \\
\hline \multicolumn{7}{|l|}{ Age (vs <35 years) } \\
\hline Age $\geq 35$ years & 1.922 & $1.299-2.187$ & 0.001 & 1.992 & $1.188-3.342$ & 0.009 \\
\hline \multicolumn{7}{|l|}{ Bleeding score (vs none) $\dagger$} \\
\hline Score 2 (pictorial blood loss chart) & 1.435 & $1.165-1.767$ & 0.001 & 2.339 & $1.250-4.376$ & 0.008 \\
\hline \multicolumn{7}{|l|}{ Pain (vs none) $\ddagger$} \\
\hline Moderate/severe & 1.346 & $1.063-1.705$ & 0.014 & - & - & - \\
\hline Gestational age (days) & 0.969 & $0.954-0.984$ & $<0.0001$ & 1.172 & $1.125-1.222$ & $<0.0001$ \\
\hline Absence of fetal heart pulsation & 24.737 & $16.579-36.911$ & $<0.0001$ & 3.573 & $1.867-6.838$ & $<0.0001$ \\
\hline Absence of gestational sac & 26.538 & $8.620-81.702$ & $<0.0001$ & - & - & - \\
\hline Mean gestational sac size $(\mathrm{mm}) \S$ & 0.879 & $0.860-0.898$ & $<0.0001$ & 0.939 & $0.897-0.982$ & 0.006 \\
\hline Absence of yolk sac & 5.782 & $3.969-8.422$ & $<0.0001$ & 4.733 & $2.110-10.619$ & $<0.0001$ \\
\hline Mean yolk sac size $(\mathrm{mm}) \|$ & 0.684 & $0.617-0.759$ & $<0.0001$ & 1.245 & $1.057-1.466$ & 0.009 \\
\hline \multicolumn{7}{|l|}{ Subchorionic haematoma (vs none) } \\
\hline Large (ratio $\geq 0.5$ ) & 1.882 & $1.074-3.299$ & 0.027 & - & - & - \\
\hline Absence of fetal pole & 10.326 & $6.991-15.252$ & $<0.0001$ & - & - & - \\
\hline Fetal size $(\mathrm{mm})^{\star *}$ & 0.789 & $0.745-0.835$ & $<0.0001$ & 0.822 & $0.771-0.877$ & $<0.0001$ \\
\hline
\end{tabular}

Abbreviations: $\mathrm{aOR}=$ adjusted odds ratio; $\mathrm{Cl}=$ confidence interval; $\mathrm{OR}=$ odds ratio

$\log (Y)=-8.919+0.689 \times(\mathrm{I}$ if age $\geq 35$ years, else 0$)+0.850 \times(\mathrm{I}$ if bleeding $\geq 1$ pad/day, else 0$)+0.159 \times$ gestation in days $+1.273 \times(\mathrm{I}$ if fetal pulsations

absent, else 0$)+1.555$ ( I if yolk sac absent, else 0$)+0.219 \times$ mean yolk sac size in $\mathrm{mm}-0.063 \times$ mean gestational sac size in $\mathrm{mm}-0.196 \times$ fetal size in $\mathrm{mm}$

* Only ORs significant in multivariate analyses are shown

† Due to small sample size, women with bleeding score of 3 were grouped with women with bleeding score of 2 . Women with bleeding score of I did not differ from women with no bleeding (score of 0 ) in Fisher's exact test; these groups were also combined

‡ Initial analysis by Chi squared test indicated that women with no pain did not differ from women with mild pain; therefore, these groups were combined

$\S$ Pregnancies with no gestational sac were assigned a value of $0 \mathrm{~mm}$

$\|$ Pregnancies with no yolk sac were assigned a value of $0 \mathrm{~mm}$

II Initial analysis by Chi squared test indicated that women with small and medium ratio did not differ from women with no haematoma; therefore, these groups were combined

*** Pregnancies with no recorded fetal size were assigned a value of $0 \mathrm{~mm}$

enabled assessment of discriminatory performance of the scoring system; it also allowed identification of predictors of miscarriage in our cohort of Chinese women and provided estimated sensitivities $( \pm 5 \%)$ at specific viability scores. Whereas only $10 \%$ of included patients were of Asian ethnicity in the study by Bottomley et al, ${ }^{11}$ our study was performed in a homogenous Chinese population; therefore, our findings suggest that the score is likely to be valid for various Asian populations, although further studies are necessary to validate its use in different Asian subgroups.

This scoring system was designed for use in all pregnant women with an intrauterine pregnancy before 12 weeks of gestation. Our analysis of the performance of this scoring system in pregnancies with uncertain viability alone also showed reasonable performance: pregnancy failure could be predicted in women with pregnancies of uncertain viability, with an area under the ROC curve of $>0.5$. However, this finding should be interpreted with caution, because there were only 223 women in this subgroup; our

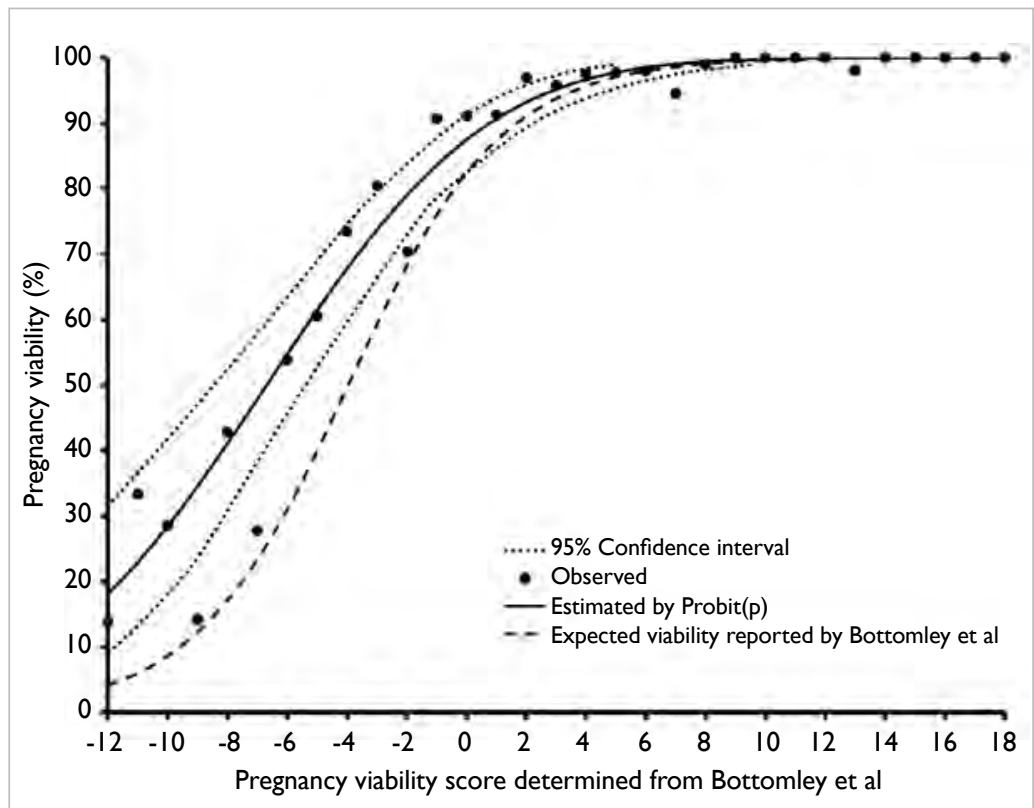

FIG 2. Observed and estimated likelihood of viable pregnancy beyond first trimester in our cohort, compared with likelihood reported by Bottomley et al "I 
TABLE 3. Observed and estimated likelihood of viable pregnancy beyond the first trimester in our cohort of 1271 women based on the Bottomley score, compared with likelihood reported by Bottomley et al ${ }^{\prime \prime}$

\begin{tabular}{|c|c|c|c|c|c|}
\hline \multirow[t]{2}{*}{ Score } & \multicolumn{2}{|c|}{ Pregnancies } & \multirow{2}{*}{$\begin{array}{c}\text { Observed } \\
\text { viability (\%) }\end{array}$} & \multirow{2}{*}{$\begin{array}{c}\text { Estimated } \\
\text { viability (\%) }\end{array}$} & \multirow{2}{*}{$\begin{array}{c}\text { Viability reported } \\
\text { by Bottomley } \\
\text { et al }{ }^{11}\end{array}$} \\
\hline & Viable & Total & & & \\
\hline-12 & 5 & 36 & $13.9 \%$ & $18.1 \%$ & $4 \%$ \\
\hline-11 & 2 & 6 & $33.3 \%$ & $23.0 \%$ & $6.0 \%$ \\
\hline-10 & 2 & 7 & $28.6 \%$ & $28.5 \%$ & $8.7 \%$ \\
\hline-9 & 1 & 7 & $14.3 \%$ & $34.6 \%$ & $12.3 \%$ \\
\hline-8 & 9 & 21 & $42.9 \%$ & $41.1 \%$ & $17.2 \%$ \\
\hline-7 & 5 & 18 & $27.8 \%$ & $47.9 \%$ & $23.4 \%$ \\
\hline-6 & 21 & 39 & $53.8 \%$ & $54.8 \%$ & $31.1 \%$ \\
\hline-5 & 20 & 33 & $60.6 \%$ & $61.5 \%$ & $40.0 \%$ \\
\hline-4 & 25 & 34 & $73.5 \%$ & $67.9 \%$ & $49.7 \%$ \\
\hline-3 & 33 & 41 & $80.5 \%$ & $73.7 \%$ & $59.3 \%$ \\
\hline-2 & 31 & 44 & $70.5 \%$ & $79.0 \%$ & $68.3 \%$ \\
\hline-1 & 39 & 43 & $90.7 \%$ & $83.6 \%$ & $76.1 \%$ \\
\hline 0 & 62 & 68 & $91.2 \%$ & $87.5 \%$ & $82.5 \%$ \\
\hline 1 & 42 & 46 & $91.3 \%$ & $90.7 \%$ & $87.4 \%$ \\
\hline 2 & 64 & 66 & $97.0 \%$ & $93.3 \%$ & $91.1 \%$ \\
\hline 3 & 93 & 97 & $95.9 \%$ & $95.2 \%$ & $93.8 \%$ \\
\hline 4 & 39 & 40 & $97.5 \%$ & $96.7 \%$ & $95.7 \%$ \\
\hline 5 & 87 & 89 & $97.8 \%$ & $97.8 \%$ & $97.1 \%$ \\
\hline 6 & 49 & 50 & $98.0 \%$ & $98.5 \%$ & $98.0 \%$ \\
\hline 7 & 35 & 37 & $94.6 \%$ & $99.1 \%$ & $98.6 \%$ \\
\hline 8 & 106 & 107 & $99.1 \%$ & $99.4 \%$ & $99.1 \%$ \\
\hline 9 & 24 & 24 & $100.0 \%$ & $99.7 \%$ & $99.4 \%$ \\
\hline 10 & 65 & 65 & $100.0 \%$ & $99.8 \%$ & $99.6 \%$ \\
\hline 11 & 40 & 40 & $100.0 \%$ & $99.9 \%$ & $99.7 \%$ \\
\hline 12 & 27 & 27 & $100.0 \%$ & $99.9 \%$ & $99.8 \%$ \\
\hline 13 & 53 & 54 & $98.1 \%$ & $100.0 \%$ & - \\
\hline 14 & 16 & 16 & $100.0 \%$ & $100.0 \%$ & - \\
\hline 15 & 21 & 21 & $100.0 \%$ & $100.0 \%$ & - \\
\hline 16 & 22 & 22 & $100.0 \%$ & $100.0 \%$ & - \\
\hline 17 & 9 & 9 & $100.0 \%$ & $100.0 \%$ & - \\
\hline 18 & 64 & 64 & $100.0 \%$ & $100.0 \%$ & - \\
\hline
\end{tabular}

sample size was only sufficient to detect an area under the ROC curve of 0.65 , assuming that the ratio of miscarriage to viability was $1: 1$. Of note, while the scoring system was reliable for estimation of pregnancy viability until 16 weeks of gestation, the implication of each score differed, compared with the previous study. ${ }^{11}$

Lastly, the miscarriage rate in this study was $13 \%$, approximately $50 \%$ lower than the $20 \%$ to $30 \%$ rates reported by Kong et $\mathrm{al}^{1}$ and Bottomley et al. ${ }^{11}$ However, the observed rate of miscarriage among women with intrauterine pregnancy of uncertain viability at presentation was consistent with the rates observed in other studies. ${ }^{11,12}$ The relatively low overall miscarriage rate could have been due to differences in local referral practices, because some women attending our EPAC were asymptomatic, whereas women with heavy vaginal bleeding or severe abdominal pain might have been admitted directly for treatment; we were unable to ascertain how many women with early pregnancy loss were directly admitted without referral to the EPAC. We excluded women with ectopic pregnancy or pregnancy of unknown location because these women had empty uteri. By focusing on women with intrauterine pregnancy irrespective of viability, we presumed that our study would be more likely to generate useful clinical information for counselling if the model were validated. Notably, excluded women comprised only $0.9 \%$ of all women invited to participate in the study.

Other potential explanations for the low miscarriage rate could be differences in lifestyle factors, such as smoking and alcohol consumption, as well as incidence of obesity; in contrast to the findings in published literature, ${ }^{23,24}$ these factors were not associated with pregnancy outcome. Smoking during pregnancy is rare in Chinese women. ${ }^{25}$ Obesity is also uncommon; in the present study only 35 women $(2.7 \%)$ had a BMI $\geq 30 \mathrm{~kg} / \mathrm{m}^{2}$, while the median weight of $53.3 \mathrm{~kg}$ and median BMI of approximately $21-21.5 \mathrm{~kg} / \mathrm{m}^{2}$ in this study were similar to the characteristics of women attending a first trimester Down syndrome screening clinic and of pregnant women enrolled in another prospective study (regarding the pelvic floor) in our centre. ${ }^{26,27}$ Lastly, the median duration of gestation at presentation to EPAC was 55 days in our study, whereas it was 50 days in the study by Bottomley et al. ${ }^{11}$ This could have contributed to our lower miscarriage rate, which decreases with gestational age.

Consistent with the findings of other studies, our multivariate analysis indicated that the following factors were associated with increased likelihood of miscarriage: increasing age, absence of fetal heart pulsation, heavier bleeding, and a large subchorionic haematoma. In addition to miscarriage, subchorionic haematoma increases the risk of placental abruption and preterm premature rupture of membranes. ${ }^{28}$ We previously proposed classification of the three sizes of the subchorionic haematoma, in relation to gestational sac size. ${ }^{29}$ We suggested assessment of the size of subchorionic haematoma relative to the gestational sac, rather than the mere presence or absolute size of subchorionic haematoma, in accordance with the approach used by clinicians in the United States. ${ }^{30}$ This parameter was expected to enhance prediction of miscarriage, but this 
hypothesis was not supported by multivariate analysis results; further studies are needed to more thoroughly investigate the usefulness of this parameter.

\section{Conclusion}

The results of our external validation study suggested that the scoring system would reliably predict probable pregnancy viability, despite slight differences in score implication. Application of this score could potentially enhance the treatment of women who initially present with early pregnancy complications. The cut-off value obtained in this study may be useful when counselling pregnant women. Further studies will be performed in our study centre to determine whether this externally validated scoring system could be utilised to reduce psychological morbidity by reassuring the women likely to maintain a viable pregnancy, while psychologically preparing other women for expected miscarriage.

\section{Author contributions}

Concept or design: OYK Wan, SSC Chan, JPW Chung. Acquisition of data: OYK Wan, JWK Kwok.

Analysis or interpretation of data: OYK Wan, JWK Kwok, DS Sahota.

Drafting of the manuscript: OYK Wan, DS Sahota, TTH Lao. Critical revision of the manuscript for important intellectual content: OYK Wan, SSC Chan, JPW Chung, TTH Lao, DS Sahota.

All authors had full access to the data, contributed to the study, approved the final version for publication, and take responsibility for its accuracy and integrity.

\section{Conflicts of interest}

As an editor of the journal, JPW Chung was not involved in the peer review process. The remaining authors have no conflicts of interest to disclose.

\section{Declaration}

The results from this research have been presented, in part, at the following conferences:

1. Wan O, Chan SS, Kong G. A prospective observational study to validate the reliability of the early pregnancy viability scoring system. Ultrasound Obstet Gynecol 2015;46(Suppl 1):42. (Oral presentation)

2. Kwok J, Wan O, Chan SS. Subchorionic hematoma: its size and association with early pregnancy outcome. Ultrasound Obstet Gynecol 2015;46(Suppl 1):172. (Poster presentation)

3. Wan OY, Chan SS, Kong GW. A prospective observational study to validate the reliability of the early pregnancy viability scoring system. FOCUS in O\&G 2015 Congress; 2015. May 30-31; Shatin, Hong Kong. The Chinese University of Hong Kong; 2015. (Oral presentation)

4. Wan OY, Chan SS, Kong GW. External validation of an early pregnancy viability prediction model via a prospective observational study. RCOG World Congress;
2016. Jun 20-22; Birmingham: United Kingdom; 2016.

(Poster presentation)

\section{Funding/support}

This research was supported by a research grant from the Health and Medical Research Fund of Food and Health Bureau, Hong Kong SAR (HMRF Reference: 12131091). The study sponsor was not involved in the collection, analysis, or interpretation of data, or in the writing of the manuscript.

\section{Ethics approval}

Ethics approval was obtained from the Joint Chinese University of Hong Kong-New Territories East Cluster Clinical Research Ethics Committee (Ref CREC-2013.348). Written informed consent was obtained from all the participants.

\section{References}

1. Kong GW, Lok IH, Yiu AK, Hui AS, Lai BP, Chung TK. Clinical and psychological impact after surgical, medical or expectant management of first-trimester miscarriage-a randomised controlled trial. Aust N Z J Obstet Gynaecol 2013;53:170-7.

2. Lok IH, Yip AS, Lee DT, Sahota D, Chung TK. A 1-year longitudinal study of psychological morbidity after miscarriage. Fertil Steril 2010;93:1966-75.

3. Elson J, Salim R, Tailor A, Banerjee S, Zosmer N, Jurkovic D. Prediction of early pregnancy viability in the absence of an ultrasonically detectable embryo. Ultrasound Obstet Gynecol 2003;21:57-61.

4. Volgsten H, Jansson C, Darj E, Stavreus-Evers A. Women's experiences of miscarriage related to diagnosis, duration, and type of treatment. Acta Obstet Gynecol Scand 2018;97:1491-8.

5. Hong Kong College of Obstetricians and Gynaecologists. Territory-wide Obstetrics and Gynaecology Audit Report 2009. Hong Kong College of Obstetricians and Gynaecologists; 2014.

6. Abdallah Y, Daemen A, Guha S, et al. Gestational sac and embryonic growth are not useful as criteria to define miscarriage: a multicenter observational study. Ultrasound Obstet Gynecol 2011;38:503-9.

7. Bottomley $C$, Bourne $T$. Dating and growth in the first trimester. Best Pract Res Clin Obstet Gynaecol 2009;23:439-52.

8. Doubilet PM. Should a first trimester dating scan be routine for all pregnancies? Semin Perinatol 2013;37:307-9.

9. Oates J, Casikar I, Campain A, et al. A prediction model for viability at the end of the first trimester after a single early pregnancy evaluation. Aust N Z J Obstet Gynaecol 2013;53:51-7.

10. Stamatopoulos N, Lu C, Casikar I, et al. Prediction of subsequent miscarriage risk in women who present with a viable pregnancy at the first early pregnancy scan. Aust $\mathrm{N}$ Z J Obstet Gynaecol 2015;55:464-72.

11. Bottomley C, Van Belle V, Kirk E, Van Huffel S, Timmerman D, Bourne T. Accurate prediction of pregnancy viability by means of a simple scoring system. Hum Reprod 2013;28:6876.

12. Guha S, Van Belle V, Bottomley C, et al. External validation of models and simple scoring systems to predict miscarriage in intrauterine pregnancies of uncertain viability. Hum Reprod 2013;28:2905-11. 
13. Ku CW, Allen JC Jr, Malhotra R, et al. How can we better predict the risk of spontaneous miscarriage among women experiencing threatened miscarriage? Gynecol Endocrinol 2015;31:647-51.

14. Pillai RN, Konje JC, Richardson M, Tincello DG, Potdar N. Prediction of miscarriage in women with viable intrauterine pregnancy-a systematic review and diagnostic accuracy meta-analysis. Eur J Obstet Gynecol Reprod Biol 2018;220:122-31.

15. Mukherjee S, Velez Edwards DR, Baird DD, Savitz DA, Hartmann KE. Risk of miscarriage among black women and white women in a U.S. prospective cohort study. Am J Epidemiol 2013;177:1271-8.

16. Khalil A, Rezende J, Akolekar R, Syngelaki A, Nicolaides KH. Maternal racial origin and adverse pregnancy outcome: a cohort study. Ultrasound Obstet Gynaecol 2013;41:278-85.

17. Royal College of Obstetricians and Gynaecologists. The Management of Early Pregnancy Loss. Green-top Guideline No 25, 2006. Available from: http://www.jsog. org/GuideLines/The_management_of_early_pregnancy_ loss.pdf. Accessed 7 Aug 2019.

18. Royal College of Obstetricians and Gynaecologists. Addendum to GTG No 25 (Oct 2006). Available from: https://www.rcog.org.uk/globalassets/documents/news/ addendum-to-gtg-no-25.pdf. Accessed 7 Aug 2019.

19. National Institute for Health and Care Excellence. Ectopic pregnancy and miscarriage: diagnosis and initial management. Clinical guideline [CG154]. Available from: https://www.nice.org.uk/Guidance/CG154. Accessed 7 Aug 2019.

20. National Institute for Health and Care Excellence. Smoking: stopping in pregnancy and after childbirth. Public Health guideline [PH26]. Available from: https://www.nice.org. uk/guidance/ph26. Accessed 7 Aug 2019.

21. National Institute for Health and Care Excellence.
Antenatal care for uncomplicated pregnancies. Clinical guideline [CG62]. Available from: https://www.nice.org. uk/Guidance/CG62. Accessed 7 Aug 2019.

22. WHO Expert Consultation. Appropriate body-mass index for Asian populations and its implications for policy and intervention strategies. Lancet 2004;363:157-63.

23. Pan $Y$, Zhang S, Wang Q, et al. Investigating the association between prepregnancy body mass index and adverse pregnancy outcomes: a large cohort study of 536098 Chinese pregnant women in rural China. BMJ Open 2016;6:e011227.

24. Pineles BL, Park E, Samet JM. Systematic review and metaanalysis of miscarriage and maternal exposure to tobacco smoke during pregnancy. Am J Epidemiol 2014;179:80723.

25. Kong GW, Tam WH, Sahota DS, Nelson EA. Smoking pattern during pregnancy in Hong Kong Chinese. Aust N Z J Obstet Gynaecol 2008;48:280-5.

26. Sahota DS, Leung WC, Chan WP, To WW, Lau ET, Leung TY. Prospective assessment of the Hong Kong Hospital Authority universal Down syndrome screening programme. Hong Kong Med J 2013;19:101-8.

27. Chan SS, Cheung RY, Yiu AK, et al. Prevalence of levator ani muscle injury in Chinese women after first delivery. Ultrasound Obstet Gynecol 2012;39:704-9.

28. Tuuli MG, Norman SM, Odibo AO, Macones GA, Cahill AG. Perinatal outcomes in women with subchorionic hematoma: a systematic review and meta-analysis. Obstet Gynecol 2011;117:1205-12.

29. Kwok J, Wan O, Chan SS. P16.02: Subchorionic hematoma: its size and association with early pregnancy outcome. Ultrasound Obstet Gynecol 2015;46(Suppl 1):172.

30. Heller HT, Asch EA, Durfee SM, et al. Subchorionic hematoma: correlation of grading techniques with first-trimester pregnancy outcome. J Ultrasound Med 2018;37:1725-32. 